WellBeing International

WBI Studies Repository

1996

\title{
The Caring Sleuth: Portrait of an Animal Rights Activist
}

Kenneth J. Shapiro

Animals and Society Institute

Follow this and additional works at: https://www.wellbeingintlstudiesrepository.org/acwp_awap

Part of the Animal Studies Commons, Civic and Community Engagement Commons, and the Politics and Social Change Commons

\section{Recommended Citation}

Shapiro, Kenneth J., "The Caring Sleuth: Portrait of an Animal Rights Activist" (1996). Animal Welfare Collection. 30.

https://www.wellbeingintlstudiesrepository.org/acwp_awap/30

This material is brought to you for free and open access by WellBeing International. It has been accepted for inclusion by an authorized administrator of the WBI Studies Repository. For more information, please contact wbisr-info@wellbeingintl.org.

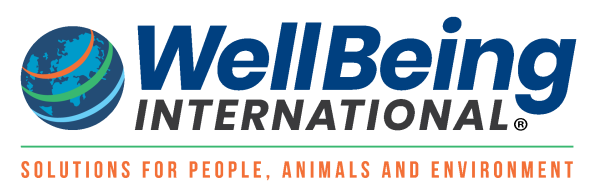


The Caring Sleuth: Portrait of an Animal Rights Activist

\section{Kenneth Shapiro}

PSYCHOLOGISTS FOR THE ETHICAL TREATMENT OF ANIMALS

The present study of the psychology of animal rights activists utilizes a qualitative analytic method based on two forms of data: a set of questionnaire protocols completed by grassroots activists and of autobiographical accounts by movement leaders. The resultant account keys on the following descriptives: (1) an attitude of caring, (2) suffering as an habitual object of perception, and (3) the aggressive and skillful uncovering and investigation of instances of suffering. In a final section, the investigator discusses tensions and conflicts arising from these three themes and various ways of attempting to resolve them.

Manny Bernstein recalls the German shepherd who licked his toddler face when he fell off his tricycle, and the sadness he felt looking at a gorilla confined in a barren cage at the local zoo. Shortly after, at the age of six, Bernstein donned a Batman cape inscribed with the letters AP (for "animal pals") and liberated Goldie, his goldfish, into a nearby drainage ditch. Ingrid Newkirk, as a girl of fourteen in India, watched in horror through a window as an ox cart driver prodded his beast by thrusting his driving stick deep into the animal's rectum.

As adults, Bernstein and Newkirk are both animal rights activists. When he is not treating patients suffering from multiple personality disorder, clinical psychologist Bernstein edits and produces a journal on alternatives to animal-based research and, in various arenas, pressures research psychologists to alleviate animal suffering and, eventually, liberate their own Goldies. As founding director of People for the Ethical Treatment of Animals, Newkirk's window now opens onto the interior of a busy office complex, but she is still drawn to suffering. She oversees a sophisticated investigatory apparatus that can reach into the locked files of the posh headquarters of a Paris-based cosmetic firm to find and follow an intricate trail: from the sales records of a shampoo, to one of its ingredients, to a laboratory that tested it on the shaved skin or eyes of rabbits locked in stockades.

Who are the animal rights activists, both national leaders and grassroots workers? How do they live, what is their daily round, how did they get to be that way? This study attempts to answer these questions through the application of a method of qualitative analysis.

Neither Bernstein nor Newkirk is a "terrorist in a stocking mask," nor a "little old lady in tennis shoes." The latter discriminatory stereotype trivialized an earlier animal protection movement by portraying its adherents as ineffectual. More recently, the press's conferral of the terrorist image on contemporary animal advocates has threatened to discredit the current movement by marginalizing it as extremist.

Recent literature in the social sciences attempts to provide a more veridical understanding than does at least the sensational press. In his study of the activists who attended a major demonstration in washington DC, Plous found a diversity of viewpoints, lifestyles and objectives that do not fit neatly into any one image or stereotype. $i$ sperling found parallels between the contemporary movement and an earlier Victorian antivivisectionist movement. ii Both arose in response to new scientific and technological developments viewed as dangerous or undesirable. In both movements, the concern with animal suffering is a convenient symbol for a broader 
evangelical and millenarian agenda. While distinguishing between welfarists, pragmatists and fundamentalists, Jasper and Nelkin described the movement as a moral crusade.iii Its members have genuine moral concerns and are on a well-intentioned quest. However, they also, particularly the fundamentalist subgroup, are quixotic and uncompromising. While not necessarily antiscience, their views of animals are not based on scientific understanding. Herzog likened activists to religious convertees, noting that they experience changes in fundamental belief and lifestyle, have a missionary zeal, and are often dogmatic in their positions. iv, ${ }^{v}$

Other studies do not support the association of animal rights activism with fundamentalism. Richards and Krannich found that activists typically belong to several other socially progressive or liberal movements, notably civil rights, environmentalism and feminism.vi Kimball found that liberal members of Congress vote for pro-animal legislation more often than do conservative members. vii

In his review of sperling's work, Magel identifies a pitfall of some of the social scientific literature: "My last and most important criticism is that Sperling ignores the essential nature of the animal rights movement. In her analysis, animals [and animal experiments] are symbols of something else. Very much to the contrary, the animal rights movement is concerned about the animals themselves.viii" of course, these are not mutually exclusive possibilities - the animal as a symbol and as an object of concern in his or her own right.

However, in the present study, I try to stay close to the immediate experience, activities and personal development of activists. While my approach may miss some of the historical backdrops, cultural contexts and symbolic meanings of the movement, it hopefully provides a portrait of the animal rights activist that captures how they manifestly relate to animals, the movement and its opposition.

\section{Method}

The data consists of two sets of materials. First, a set of fourteen autobiographies of leaders of the movement, all save one published between 1986 and 1991 in Between the Species: A Journal of Ethics. As the distribution of this publication is largely within the movement, the personal accounts are probably more confessional than promotional or tactical in intent. All but three are US-based.

The second set consists of 21 survey protocols of grassroots activists solicited at an animal rights conference in 1991. The survey consisted of two semi-structured questions: (1) Describe the situation in which you first realized that you had a special interest in nonhuman animals. Estimate your age at the time. (2) What is it like to be an animal rights activist? Respond by describing a recent situation in which you clearly were being an animal rights activist. What was going on, what were you experiencing?

Consistent with other studies reporting on the gender constitution of the animal rights movement, the sample was predominantly female (23 of 35). ix, ${ }^{x}$ However, again consistent with other findings, the leadership was predominantly male ( 9 of 14 ). Most of the grassroots activists had at least a college education, and most spent at least 30 hours per week in their movement activities.

The analysis of data employed a modified version of a method developed in phenomenological psychology. $x i$ As described by Wertz, in this qualitative method the investigator "demarcates meaning units" in each individual protocol to arrive at a description from a "first person perspective, more or 
less in the subject's own language".xii The investigator then performs a "psychological reflection" to describe each individual account "as

experienced, as behaved, or more generally as meant by the subject." Finally, through a second psychological reflection, the investigator arrives at a more generalized account of the structures of experience exemplified in the individual accounts. The primary finding of the study is a statement of this "general psychological structure." This description consists of the psychological meanings of the structure, and is not necessarily in the subjects' own language.

This method and form of results keys on the similar or common structures in the phenomenon under investigation. Of course, this does not exclude the existence of variations within the common constitutive or defining features.

Phenomenological psychology is an interpretative approach which accepts the necessity of investigator participation and denies the objectivistic ideal of detachment (cf. participant observation in anthropology and ethnomethodology in sociology). It is, then, appropriate for the investigator to explicitly identify his or her point of view in approaching the study. In addition to being trained as a phenomenological psychologist and a clinical psychologist, for the past 12 years I have been involved in the animal rights movement at both the national and grassroots levels.

\section{Results}

Here I present a summary account of the experience of being an animal rights activist. The materials examined suggested organization into five themes. Following this description of the general psychological structure of this experience, the balance of the paper provides further exposition, discusses selected issues raised by the themes, and speculates about connections to other general psychological literature.

An animal rights activist is an individual (1) whose primary concern is caring about animals; (2) who is primed to see suffering in animals; (3) who aggressively seeks out and skillfully investigates situations in which animals are suffering; and (4) for whom such caring, seeing and seeking become pervasive aspects of daily life, embodied in his or her lifestyle. (5) Tensions between the apparent contradiction between an attitude of caring and the aggressive exposure of human-originated animal suffering are resolved in one of several ways: embracing, suppressing or losing touch with the caring.

\section{Caring}

Animal rights activists have a caring attitude toward nonhuman animals. Consider "attitude" here not as a specific belief about something - the earth is flat - but as something like the adolescent behavior of "copping an attitude." We are all familiar with the infuriating tone, disdainful gesture, slouching posture, and "cool" response to even the most serious situations that characterize teenagers. While limited to a particular developmental stage and usually transparently defensive, such an attitude is a pervasive personal style - an habitual way of experiencing and expressing the world through the body.

Caring about nonhuman animals is such an attitude. It means being attentive to them in a watchful and concerned way. More than just curiosity or interest, it is a positive inclining or leaning toward them, a sympathy for them and their needs. A caring attitude is one of continuous sensitivity and responsiveness, not a transitory awareness or a momentary concern. 
Most activists report having some inkling of the attitude of caring in childhood, often between the ages of 5 and 10 years old. Although not consciously adopted, for some it immediately becomes an habitual style, pervasively coloring most aspects of life. Others report a recrudescence, a more conscious adoption of the attitude in early adulthood, perhaps an intellectual awakening occasioned by reading Peter Singer's Animal Liberation. Xiii

For other activists the moment of discovery is decidedly less cerebral. Like Newkirk's, the awakening of Helen Jones, founder of the International Society for Animal Rights, took place in an atmosphere of trauma:

My first awareness of animal suffering was at the age of four or five. My mother took me to a zoo. As we entered we saw a large white rabbit, transfixed with fear, in a cage with a snake. Within a second or two the snake began swallowing the rabbit.... My mother never again entered a zoo. I did, many years later, only to collect evidence for a legal case. Xiv

Michael Fox, senior staff member of the Humane Society of the United States, describes a very different experience:

My first encounter with the miraculous and the mystical was as a child. I had a playground full of miracles.... Like the child in walt Whitman's poem who went out into the world and became all that he perceived, I entered the mystical world of nature that my miraculous playground embraced, and became a part of everything... To play with a pond...to "mind" everything that I perceived in it, on it and around it... xv

Such first moments of absorption in other beings are an emotional and intuitive grasp of a relation rather than an intellectual justification of it. They are moments of the heart, not of the brain. The caring attitude is not itself a philosophical position, although it is the experiential bedrock for any philosophy that is more than sterile intellectual discourse.

For most people, however, the initial recognition is likely to involve a dog or a cat rather than a zoo animal or the amphibian denizens of Fox's boyhood Derbyshire pond. Adopting and living with a companion animal promotes a poignant awareness of the caring connection, one that is sometimes only fully realized in grief at the death of the animal. Tom Regan, author of the seminal work on animal rights philosophy, writes that although he entered the movement through Gandhi's views on nonviolence to animals, it was "the death of our dog that awakened my heart."xvi, xvii

A few activists report having what can be described as a conversion experience, a moment of sudden awareness that the path they have been following is strikingly uncaring. After years of research testing the toxic effects of radiation on primates, Don Barnes, now of the National AntiVivisection Society, dramatically discovered and adopted a view that made continuing this work utterly unthinkable.

However they occur, these are wrenching moments. There is shock in recognizing that it is possible, perhaps morally obligatory, to care about these others. It is as if one suddenly realizes that sitting in the next room is a family member whom one has somehow forgotten - or, at least, forgotten to love. Such moments are powerful. They bring about change at the level of basic attitudes - a person's consciousness is raised. He or she becomes, in the movement's term, an "animal person." Typically, he or she adopts a 
lifestyle that carefully avoids at least the grosser forms of animal exploitation.

Does an "animal person" only care about nonhuman animals? For many activists the caring connection extends beyond animals to various classes of oppressed humans and to ecosystems that include animals, humans, trees, and even rocks. A poll of subscribers to Animals' Agenda, a leading magazine of the movement, showing that the great majority are or have been active in other progressive social movements supports this generality of the caring attitude.xviii Broida, Tingley, Kimball, and Miele found that undergraduates who take a position critical of animal research are more likely than uncritical students to have a personality profile associated with counseling, teaching, and other helping (caring) professions.xix

In the other direction, Hills found that people who like people (peopleoriented) also like animals, more than do thing-oriented people. $x x$ Historically, Henry Bergh, founder of the American Society for the Protection of Animals also helped form the New York Society for the Prevention of cruelty to Children and Frances Cobbe, a leader of anti-vivisectionism in

late 19th century England, was also a leading feminist.xxi

What is the developmental origin of this caring attitude? Our speculations here must take into account the fact that, according to the Agenda survey and other studies, roughly $75 \%$ of movement activists are women. We will consider three lines of argument.

The first has to do with social conditioning. Although child-rearing practices and cultural expectations are changing, girls' socialization still tends to foster nurturing, responsiveness, and caring behavior. Carol Gilligan has demonstrated that this difference in gender training affects not only behavior but the acquisition of a different moral framework. xxii Girls develop an ethic built on responsiveness to the needs of others in a personal setting, while boys forge a justice ethic based on abstract rules and universal principles.

A related explanation of individuals' participation in the movement is the nature of caring, which is itself based on an even more fundamental attribute, an empathic style of understanding the world. As a sympathetic response, caring is a judgment about someone else's neediness. Empathy, by contrast, is a feeling but not yet a judgment of need or an attempt to alleviate another's pain. It is a way of relating to the world that focuses on and directly apprehends the feelings, motives, and interests of other beings. Fox's boyhood play "minding" a pond, becoming part of the creatures that inhabit it, is an example of the empathic style in action, as are those exhilarating moments of self-forgetfulness induced by the performance of a great actor, dancer, or musician.

As a style of understanding, empathy is readily distinguishable from objective understanding, in which we try to stay outside an experience and our personal responses to it. The paradigm of objective understanding is experimental science.

A child's understanding of the world begins with something closer to empathy than to objective knowledge. After an early stage in which the child feels the mother's love or anxiety by a kind of immediate contagion - as if mother and child were one - he or she enters a stage Piaget calls

"animism."xxiii All objects, falling leaves, the toast popping up, as well as the meowing cat are invested with intention - the toast wants to be eaten just as the cat wants to be fed.

The first task of education is to "advance" the child, from this ensoulment of everything in the world that moves, to the more direct understanding provided by empathy. Later he or she is initiated into the task 
of constructing, primarily through inference rather than empathy, a world of impersonal objects related causally rather than intersubjectively.

This objective understanding is not gained without casualties. One cannot simultaneously infer and empathize, keep outside and go inside. Earlier empathic capabilities are subordinated and can grow rusty from disuse. Moreover, we are taught not to empathize with certain classes of objects. The deer we hunt, the chicken we eat, the mink we wear, and the frog we dissect are no longer individual subjects of a world we can empathically enter. They are objects, members of an abstract aggregate (the deer population), commodities for our consumption (meat or fur), or instruments for our

learning (organism or laboratory preparation). xxiv

objective understanding, therefore, actively devalues emotional responsiveness and intersubjectivity - which threaten to create personal involvements and so violate the ideal of neutrality. In science's adoption of this ideal, these contaminate objective understanding by giving rise to bias. If, as we have described it, the caring attitude is a leaning toward, objective understanding cannot be caring. By contrast, empathy, although it is not yet a judgment or leaning, readily lends itself to caring. When I empathize with you I experience, directly and intimately, what you need; we are close, if only for a moment and only imperfectly, for I have cohabited your world. If the paradigm of objective understanding is science, that of empathic understanding is care-taking.

The respective converses are also possible. I can exploit you more effectively by knowing your needs at the close hand provided by empathy; and I can care for you more effectively when I have coolly and objectively determined your needs. Nonetheless, it is clear, on psychological grounds, that empathy facilitates caring and, from the historical record, that objectification is the handmaiden of instrumental use - that is, of exploitation.

During childhood, both sexes learn to abandon the bald egocentrism of infancy. In general, girls are socialized to leave the self through immediate empathic involvement in another person, while boys are encouraged to assimilate the self to an objectified understanding of the wider world. It therefore follows that women in the animal rights movement outnumber men because they have been socialized to retain an empathic style of understanding and a personal style of relatedness - subject to subject rather than subject to object.

A third explanation of the origin of the caring attitude suggests that it is based on identification with the oppressed. According to this analysis, because women in western culture are themselves oppressed, they are more likely than men to identify with other oppressed groups and so to predominate in numbers (though not in leadership roles) in progressive social movements. Moreover, women's identification with nonhuman animals may occur because their oppression shares certain structural and linguistic terms. XXV Both women and animals require "husbanding" (husband, husbandry); both can be a good piece of meat ("Are you a breast or a leg man?" - advertisement for Purdue chicken); and both are fair game (objects of the hunt).

\section{Seeing suffering}

In the sketch of his childhood, Bernstein relates that even at the age of four or five he saw the suffering of nonhuman animals. The ability to see suffering is characteristic of animal rights activists; their solicitous leaning toward animals positions them to notice their suffering.

But how does this distinguish them from anyone else? Surely everyone can see suffering? On the contrary, many, if not most people, do not see it. To 
understand how this is possible, we need to clarify what it means to see, exploring two different perspectives - one dealing with human perception and the second with its object, in this case nonhuman animals.

As there are different styles of understanding so there are different styles of seeing. Two people look at a person wearing a fur coat. One sees elegance and beauty, the second sees dead animals and the suffering and exploitation they underwent when alive. In spite of the movement's public exposés of the fur business, some people remain genuinely ignorant of the living and dying conditions of trapped and ranch animals; and, of course, individuals have different interests and values. Other people, however, literally do not perceive the suffering because of a particular style of seeing akin to denial, an unwitting disavowal of certain emotionally laden themes or issues. Questioned directly, such individuals may indicate knowledge of these subjects even though they are able to block full awareness of its emotional implications.

Another style of seeing, both subtler and more common, involves a distinction between registering and reporting and leads to the claim that animal rights activists are people who consistently register suffering. xxvi Consider, for example, a visit to the museum. It is crowded; you have not allowed enough time, and you rush through the exhibition. Do you see the Rembrandt? Yes, you see it, but you do not really take it in, fully take stock of it, appropriate it. You look at it, but, while aware that this is a Rembrandt and that a Rembrandt has certain striking and inimitable features, you are too hurried to grasp them fully or let them sink in. Your style of seeing in that moment is more like receiving a report of a Rembrandt than being fully present to one.

As a group, animal rights activists see suffering in a more robust and appropriative way: they register suffering. While not radically or grossly disavowing it, most other people are conscious of it somewhat vaguely, as they were aware of the nightly body count of famine victims in a far off land, as reports of events remaining always at a distance. Even people interested in animals - the casual horseback rider, the owner of a purebred dog, the birdwatcher - are usually cognizant only of the problems of animals that are objects of their special interest.

Kim Bartlett, editor of Animal People, describes a moment in her life when a shift occurred in how she saw suffering:

Shortly after [going dove hunting], I went to a bullfight across the [South Texas] border. Nothing registered but the music. The blood didn't seem real.Xxvii

But only a few years later:

I received a piece of mail....it was about fur and contained...pictures of a fox and rabbit caught in leghold traps. The look in their eyes pierced my soul...I sat down and cried.xxviii

A combination of institutional arrangements, linguistic sleights of hand, and defensive operations sustain this style of seeing as reportage. Animals in factory farms, fur ranches, and laboratories are located at remote distances and physically hidden from us. They are maintained in aggregates that make it difficult to relate to their individual suffering. As consumers, we see them packaged in ways that conceal their animal origins and any provenance of suffering. Animals are also concealed through language "fruits of the sea." Cognitively, many people exaggerate the categorical distinctions between human and nonhuman species of animals. Such overdrawn 
distinctions then allow "outgroup biases" to come into play.Xxix These further distance "us" from "them" and support the failure to register their suffering. A final style of seeing - abstract seeing or seeing past the suffering - is found both in the movement and among its detractors. It allows us to pass over the real animal or animals before us and move to a symbolic plane. We see injustice, speciesism, or the "death of nature," not the suffering animal. Of course, no one can stay constantly in the existential moment. The fully engaged seeing, registering, leaves us vulnerable to the suffering and injustices of the world, while abstract seeing deflects and softens their impact. Eventually, we must abstract, contextualize, integrate, make sense of things.

However, these modes can also function as blocks to perception; when we adopt them as an habitual style of seeing, we lose touch with the experiential foundations of our value systems. The hunter who sees past the death throes of the buck he or she has shot to the abstraction "the deer," a "population" that needs "culling," never sees the pain. Nor, occasionally, does the animal rights activist who sees past the frustration and boredom of hens in tiers of cages the size of this page. The caged animals become a symbol for something else - perhaps the transformation of traditional agriculture to factory farming.

In addition to styles of seeing that deflect us from directly registering suffering, a prior block may occur in the nature of animals. After all, we can only see suffering if it exists; and many people, in both laboratory and slaughterhouse, have long maintained that animals do not suffer - or, at least, that we cannot know whether they do. $x x x$

Some argue, for example, that suffering - a distinct emotional response characterized by fear and anxiety - while usually associated with physical pain, is not inseparable from it. The runner who painfully but elatedly extends him or herself to cross the finish line first is not suffering. According to this reasoning, animals could experience pain without suffering. Some researchers, in fact, suggest that suffering implies an awareness that pain or distress represents a threat to one's integrity or well-being. The questioning of nonhuman animals' capacity to experience such awareness further fosters styles of seeing that fail to register animal suffering.

In addition to these considerations of the nature of nonhuman animal experience, another backdrop to seeing their suffering is the human proclivity to take nonhuman animals as metaphors of ourselves. Although some deny animals the capacity to manipulate symbols, no one denies their ability to bear them. From Aesop's fables to Kipling's Just-so stories to Disney's animations, folk and modern cultures have required animals to bear a rich load of meanings to help us understand (or just stand) ourselves. As symbols they have served as repositories of both our valorized (wise as an owl) and our denigrated (animal or bestial) human characteristics. The symbols come to function as opaque layers, masking our perception of the real animals' true nature and immediate plight. If our perception of animals is so laden with metaphors of ourselves, how can we be sure that their suffering is not our own, projected? This symbolic density also allows us to limit our experience of their suffering to reportage rather than registration.

Caring can be sentimentalized, and sensitivity to suffering can be a projection of human characteristics onto nonhuman animals. There is a minority in the movement on whom childhood exposure to the early Disney has left a certain proclivity to the maudlin. As a group, however, the caring of animal rights activists is informed by a sophisticated understanding of animals both their suffering and the institutional and ideological origins of that suffering. $x x x i$ 
Armed with this knowledge, their empathy and caring, animal rights activists register the suffering of nonhuman animals. However, while a necessary condition, the registration of suffering is not a sufficient one, for it does not yet imply a commitment to action. Animal rights activists not only know that animals suffer, they live to do something about it.

\section{Seeking suffering}

But pain and suffering are often the hidden ingredients...[so] we have to go behind the closed doors, behind the sanitized wrap...xxxii

In an earlier era, a carter beat a horse until the welts were bloody and, exhausted and overheated from the burden of pulling a heavily laden carriage, the animal collapsed on the street. Today, a research assistant takes a baboon away from her or his protesting mother, and places the infant in a cage which will serve as experimental home and school in the ensuing (de)formative months of emotional and intellectual development. The first was a highly visible public event, while the second occurs behind layers of sanitized, justificatory and obscuring wrap - federal regulations, institutional animal care and use committees, specialized scientific journal articles, high security lab facilities.

Even to the eye desensitized in the various ways I have described, public display of human induced suffering in animals is still available, and there is still individual abuse - acts defined by their aberration from norms of acceptable behavior. However, the modern era has brought its own forms of institutionalized exploitation (factory farms, "animal models" of every form of physiological and psychological disorder...) and with them new norms of the acceptable and the aberrant. To some extent a difference between the contemporary animal rights movement and its late nineteenth century predecessor is a shift in focus from policing individual abuse to the development of a radical critique of institutional practices. Indeed, part of the current debate within the movement (rights versus welfare) hinges on the philosophical and strategic merits of that shift. Yet even beneath the surveillance of individual abuse by traditional humane society officers and the desire of some to focus on improving animal welfare within present institutions lies a common impulse to effect still more fundamental structural changes.

What has shifted is less the locus of critique than the visibility of its object. The contemporary animal rights worker must actively seek suffering. To find it typically requires an investigatory posture combining classic Holmesian analysis of direct physical evidence with the use of sophisticated technological tools.

Today's activist is a skillful sleuth who has learned to follow trails through the labyrinths of democratic and bureaucratic political processes, to hear hints in diplomatic pronouncements, to defog regulatory smoke-screens, to "search" online abstracts of biomedical research proposals. Holmes' magnifying glass is of little use here for the animals are nowhere in sight. Investigative work begins with reading texts rather than with deductions from physical evidence. Even the texts, however, do not refer to animals and certainly not to their suffering. In a trade report on agricultural production, in place of animals there are numbers of pounds of meat and their market value. The animals are an absent referent, not even present by allusion. The relation between meat and living animals is unspoken as the animals who suffered and died within this productive enterprise were from the outset meat on the hoof. 
Suffering is also hidden in time: in a past traced from the eggs in the cake back to the factory farm. or it is a future event presaged by a notice of a proposed marine park and the consequent capture of dolphins to reside there to entertain us.

To the animal rights activist, these are all bloody trails - as bloody as that literal trail left by the blood and sweat of the exhausted carthorse. To discover and follow them, our latter-day Sherlock Holmes is trained in politics, diplomacy, science, economics, high-tech information retrieval; she possesses a skill in textual interpretation worthy of a postmodernist scholar. Primed by caring and sensitivity to suffering and equipped with a range of approaches, the committed activist dedicates herself to seeking and exposing suffering behind closed doors - suffering implicitly present between the lines of a bowdlerized text, beneath the red tape of a Byzantine political process, in a future only adumbrated or a past reconstructed like a revisionist history, from fragments and clues disregarded by others.

\section{Pervasiveness of the seeking}

"People who have an affinity to nonhuman beings are drawn like magnets to places where these individuals are suffering. It's a horrible thing - your car steering wheel turns to the right and off you go because down that lane there is a slaughterhouse or something."xxxiii

Moreover, sleuth work is insidious, for it is difficult to stop seeking. What begins as a certain sensibility to suffering crystallizes into an avocation volunteering at the local shelter - then becomes a vocation and, finally, turns into a way of life. Without intending it, the animal rights activist finds that she is increasingly and, eventually, perpetually on call:

To devise a political strategy is one thing. To live everyday life is another... It means to walk in the streets and see butcher shops, pharmacies, furrier shops, perfumeries, or to sit in restaurants not far from people eating animal flesh. Or to love and cherish persons who help to perpetuate the exploitation. Or to enjoy the beauty of spots and the enchantment of towns that conceal the exploitation behind the serene facades. Xxxiv

The workday of research, inquiry, and confrontation does not end neatly at the office door. Whether seeking them or not, the activist senses traces of animal suffering and exploitation all around. The street in which she walks is no longer an open road, a horizon of stimulating possibility and chance encounter, but a set of potential clues, hints, suspect provenances. All roads become part of a network of bloody trails. Paradoxically, what is everywhere hidden, forgotten, denied, erased, transmuted, manufactured is yet everywhere present. The shopping mall, the restaurant; the city, but no less the woods and the sea - each has its own network of bloody trails. For animal rights activists, there is meat in their soup, animal-based research in their medicine... They can't stop seeing or seeking the suffering.

Tensions and conflict

It is just so very troublesome to be sensitive to the suffering of others.... It takes so much out of a person and sometimes I believe it takes too much happiness away. $x x \times v$ 
The preoccupation with seeking suffering colors the physical landscape of the world. When Fox returned to the hillsides of his childhood, he saw them differently. He could no longer glory in the "mystical world of nature" and the "sense of renewal" gained through "emotional connectedness" to it. Beyond the real changes in that environment (now overstocked with sheep) and the inevitable sobriety of maturity, his loss is an occupational hazard, which perhaps has comparable forms in every social movement committed to basic change.

This (dis)coloration of the natural and animal scene also extends to the human landscape. Being a careful sleuth involves looking for trouble. Whether in the conventional style of a probe of the political process, an inquiry under the Freedom of Information Act, or in the more activist style of surveillance and infiltration, investigators are viewed by the targets of the investigation as trouble-makers. Information gained exposes and pressures those targeted to change.

On a more interpersonal level, seeing and seeking what others do not notice and do not want to notice promotes certain forms of social interaction, attempts to convince others of the presence of exploitative practices. Particularly at the grassroots level, activists often present themselves as witnesses to animal suffering, testifying to strangers, acquaintances, and intimates alike. Activists' styles vary from a cool, controlled presentation of factually and philosophically grounded arguments to an impassioned striving to find the one compelling image to cut through the rationalizations that justify suffering.

Whatever the style, these are emotionally loaded moments, and they can arouse strong feelings in even the most seasoned campaigner. Beneath the concern for the well-being of animals and the inevitable measuring of one's own effectiveness lies another set of emotional dynamics: seeking and finding suffering induce anger and indignation - at both suspected perpetrators and consumers who collaborate in exploitation. At times, the impulse to blame and treat people with scorn, or even vengeance, is difficult to resist.

Some activists throw blood on fur-wearers not so much to educate and induce change - or to tactically stigmatize a symbol of high fashion - as to transform them literally into dripping bloody trails. The desire to make the bloody trail visible merges with a wish to smear others with guilt. Moreover, the dynamics of this dramatic example can generalize to even casual encounters if chronic anger gives vent to an intolerance that is almost always counterproductive for the activist. Can these feelings be those of a caring person?

Caring and anger are not, of course, inherently contradictory. I have no doubt that I still love my son even in that moment when we are both taken aback at the strength of my outburst at the end of a long rainy Saturday afternoon. An anger laced with intolerance and entitlement, however, corrodes caring; sensibility and intolerance of others' insensibility cannot be bedfellows for long. Aggressive investigation, confrontation, protest, and demonstration often met by stonewalling and, more recently (as a result of the movement's effectiveness), by counteroffensives, can suppress caring.

These occupational tensions between caring and anger can even threaten the activist's motivation. The fact that most people go about their business as if the activist's agenda were irrelevant to the world's "real" problems while others argue that it is wrong-headed, misguided, even dangerous and unethical - induces self-doubt. Uncertainties arise about one's competence and motives, about being peripheral or weird, about missing the pleasures of a conventional life in which work is left at the office. Doubts can undermine confidence in one's account of the world and the positions taken. Perhaps, after all, the suffering is necessary; perhaps exploitation is part of the 
natural order of things. Perhaps caring and aggressively exposing suffering are contradictory, and the caring is counterfeit or on balance, hurtful.

One further twist is that the activist, in seeking out suffering, offends her own caring sensibility, incites her own pain and distress, disappointment and disillusionment. The activist is looking for trouble in the further sense that what is sought is suffering. Its discovery is itself troubling, particularly to a caring person who habitually registers that suffering. She is searching for something; she wants to find it and is committed to finding it and does not want to find it. The sense of accomplishment, even of exhilaration at finding it is, at best, bittersweet and, at worst, heartrending. In exposing the bloody trail, the animal rights activist creates her own bloody trail; human pain commingles with the animals' suffering.

In the last few years I have become increasingly aware of losing touch with something precious to me. I am standing on a cliff at the head of Linekin Bay on the coast of Maine, idly watching the sea. The tide is coming in, the breezes play on the water, fish jump at the surface, gulls careen above, an occasional osprey hovers. Idyllic, yes, but I no longer fully find it so. Something in the periphery of my awareness nags at me. I notice hundreds of parti-colored buoys polka-dotting the bay, and now I recognize what distracts me. These buoys mark the death-row cells of countless lobsters and crabs who have found their way into but not out of the sunken traps. I remember a more innocent and fully engaged participant in such panoramas, myself as I wandered through the fields and gardens of my childhood and discovered nature and animals for the first time. My first sighting of a bluebird was stunning in a way irretrievably lost to me, for bluebirds now appear in an ecology of insecticides, introduced species, habitat destruction, and managed bluebird trails.

Between the sadness and the self-questioning, an impulse to remain uninvolved, to tend one's own garden, can gain momentum.

\section{Resolutions}

How do activists deal with the melancholy, the self-doubts, and the potential alienation from the wider society? How do they choose, among the coping styles available, one that will be most constructive for the individual and for the animals?

The most common resolution, in this and other social movements, is the constitution of a community of like-minded individuals brought together through investigations, exposés, demonstrations, and conversations. As individuals and as a community, animal rights activists are privileged to live fulfilling lives in which dedication to the well-being of others extends beyond the traditional pales of family, ethnic group, or even nation. As members of the animal rights community, activists have a sense of belonging, of sharing common values and purpose. They are "at home" - with themselves, in their relations with other people and animals, in a world that they both belong in and help to form. After the rugged natural beauty of Maine with its white-water canoeing and hiking was transformed for me into a landscape booby-trapped - as my neighbor's effort to rid his garden of "nuisance" animals one day resulted in the trapping of my own beloved dog, I helped found a new home in Maine. A small group of us formed a more neighborly group who would work together to lobby against trapping, to expose mistreatment in unmarked warehouse poultry "farms" and to provide students the right to alternatives to dissection.

Ours was a community in the fullest sense of the word. Activists share not simply a workplace or a job or even a set of values but a concrete way of life embodied in daily activities. Just as nonhuman animal suffering pervades society, so every aspect of activists' lives - diet, dress, diversions - is 
designed to expunge the taint of animals exploited for human ends. They embrace caring for animals by bearing witness at every mundane turn to the possibility of living their caring within a mutually supportive community.

Yet, if this sense of community can offset the disaffection often felt with respect to the larger society, it also has its pitfalls. It may result in a heightening of insularity and, consequently, in diminished effectiveness through a pattern of preaching to the converted. It may even reduce one's usefulness to animals by the phobic constriction of one's life (e.g., avoiding driving because insects are killed against the windshield) or becoming obsessively preoccupied with one's own purity. (Is it acceptable to eat honey from free ranging bees?)

A second resolution involves suppressing the caring. Cavalieri states:

The extent and pervasiveness of animal exploitation are such that only by closing your eyes a little can we keep the hope of affecting reality, and the grit to do it. $x x x v i$

Newkirk expresses the temporary suspension of caring through a metaphor of building a "protective wall." Only by "steeling" herself, showing no emotions, is she able to do her work as a "conscientious investigator" of animal cruelty. Others suppress caring more systematically - distancing themselves from direct contact with suffering by conducting a campaign at some remove from the actual scene of the exploitation, developing and administering an animal rights organization, or writing on the issues.

A third resolution or style of coping occurs when self-righteous indignation creates an attitude more hateful than caring. More than suppressing or suspending caring, here the activist actually loses touch with it. Such a person can be a liability to the cause, playing into the efforts of vested interests in animal exploitation to polarize the movement into revolutionist and reformist camps. Often this posture of indignation involves a rigid adherence and preoccupation with principle. In place of caring and the registration of suffering, the knee-jerk application of a philosophy reduced to slogans can support an unforgiving bearing. Unwittingly, the activist collaborates with the press's readiness to oversimplify issues. The public is asked to choose between such extreme alternatives as whether or not to sacrifice a single mouse to save a million human lives, or to accept as reform a measure that allows a veal calf enough space to turn around in his crate.

To some extent, these three styles of dealing with the particular tensions inherent in this movement appear at different stages in the career of an activist. In an early stage, an individual often experiences an extended period of enthusiastic embracing of the community of caring. At a later stage, the activist realizes the depth of resistance to change and may move to a more self-protective position by suppressing the caring or by burying it beneath a rigid application of right and wrong.

Caring remains the foundation of the animal rights movement. The most accurate image of the animal rights advocate is that of a caring individual who persists in assertively and, when necessary, aggressively exposing animal suffering.

A grassroots activist writes:

I often look at things and situations in a very animal aware way. I see the degradation of animals in a lot of things. Being an animal rights activist, I feel a great urgency to change the world and I always have to deal with the fact that my ideas are not very popular...Usually people are very defensive and annoyed when I talk about animal rights...they feel 
it's an attack on them and their lifestyle and they don't see the bigger picture.

Note on Contributor

Animals: Social Scientific Studies of the Human Experience of other Animals; founding coeditor of the forthcoming Journal of Applied Animal Welfare Science (JAAWS), and president of the Board of Directors of the Animal Rights Network, publishers of The Animals' Agenda Magazine. Trained as a clinical and personality psychologist, he is author of three books, including a forthcoming critique of psychology's use of animals in research.

Notes

$\mathrm{i}_{1}$. Scott Plous, "An Attitude Survey of Animal Rights Activists," Psychological Sciences, 2, 1991, pp. 194-196.

ii Susan Sperling, Animal Liberators: Research \& Morality (Berkeley: University of California Press, 1988).

iii James M. Jasper and Dorothy Nelkin, The Animal Rights Crusade: The Growth of a Moral Protest (New York: The Free Press, 1992). iv Harold Herzog, "The Movement is My Life:" The Psychology of Animal Rights Activism, Journal of Social Issues, 49, 1993, pp. 103-121. $\mathrm{v}$ Shelley L. Galvin and Harold A. Herzog, "The Ethical Judgement of Animal Research," Ethics and Behavior, 2, 1992, pp. 263-287.

vi R.T. Richards and R.S. Krannich, "The ideology of the animal rights movement and activists' attitudes toward wildlife," Transactions of the North American Wildlife and Natural Resources Conference. vii Robert Kimball, "Liberal/Conservative Voting Records Compared to Interest in Animal Protection Bills," PSYeta Bulletin, 9, 1989, pp. 7-9. viii Charles Magel, "Animal Liberators are not Anti-Science," Between the Species, 6, 1990, pp. 204-213.

ix Jasper \& Nelkin.

$\mathrm{x}$ Plous, 1991.

xi Amedio Giorgi, Psychology as a Human Science: $A$ Phenomenologically Based Approach (New York: Harper \& Row, 1970).

xii Fred J. Wertz, "Method and Findings in a Phenomenological Psychological Study of a Complex Life-Event: Being Criminally Victimized," in Phenomenology and psychological research, ed. A. Giorgi (Pittsburgh: Duquesne University Press, 1985). xiii Peter Singer, Animal Liberation (New York: Avon, 1975). xiv Helen Jones, "Autographical Notes," Between the Species, 4, 1988, pp. $69-76$.

xv Michael W. Fox, "Autobiographical Notes," Between the Species. 3, 1987, pp. 98-101. 
xvi Tom Regan, The case for animal rights. (Berkeley: University of California Press, 1983).

xvii Tom Regan, "The Bird in the Cage: A Glimpse of my Life," Between the Species, 2, pp. 90-101.

xviii Richards and Krannich.

xix John Broida, Leanne Tingley, Robert Kimball, and Joseph Miele, "Personality Differences between Pro- and Anti-Vivisectionists," Society and Animals, 1, pp. 129-145.

$\mathrm{xx}$ Adelman M. Hills, "The Relationship between Thing-Person orientation and the Perception of Animals," Anthrozoos, 3, pp. 100-111.

xxi Richard Ryder, Animal Revolution: Changing Attitudes Toward Speciesism, (Oxford: Basil Blackwell, 1989).

xxii Carol Gilligan, In a Different Voice: Psychological Theory and Women's Development (Cambridge, MA: Harvard University Press, 1982 ).

xxiii Jean Piaget, The Child's Conception of the World, Translated by Jean and Andrew Tomlinson (New York: Harcourt, Brace \& World, 1930).

xxiv Kenneth J. Shapiro, "The Death of the Animal: Ontological Vulnerability," Between the Species, 5, pp. 183-195.

xxv Carol Adams, The Sexual Politics of Meat: A Feminist-Vegetarian Critical Theory, (New York: Continuum, 1990).

xxvi Robert Sokolowksi, Husserlian Meditations: How Words Present

Things, (Evanston: Northwestern University Press, 1974).

xxvii Kim Bartlett, Blinded by the Light: Or How Nature Triumphed over Nurturance, Between the Species, 6, pp. 94-98.

xxviii Bartlett, p. 95.

xxix Scott Plous, "Psychological Mechanisms in the Human Use of Animals," Journal of Social Issues, 49, pp. 11-53.

xxx Plous, 1993, pp. 26-7.

xxxi Stephen Kellert, "Perceptions of Animals In America," Perceptions of Animals in American Culture, ed. R. J. Hoage (Washington, DC: Smithsonian Institution Press, 1989).

xxxii Theresa C. Corrigan, "A Woman is a Horse is a Dog is a Rat: An Interview with Ingrid Newkirk," And a Deer's Ear, Eagle's Song, and Bear's Grace: Animals and Women, ed. T.C. Corrigan and S. Hoppe (Pittsburgh: Cleis Press, 1990).

xxxiii Theresea $C$. Corrigan

xxxiv Paola Cavalieri, "Reflections," Between the Species, 6, 1990, pp. 153-157.

xxxv Emmanuel Bernstein, "Empathy toward Animals and other Sentient Beings: A Very Personal Account," Between the Species, 3, 1987, pp. 149-158. 
xxxvi Cavalieri, p. 157 